\title{
Eicosanoid Activity Induction
}

National Cancer Institute

\section{Source}

National Cancer Institute. Eicosanoid Activity Induction. NCI Thesaurus. Code C41535.

Through increased production or release, or inhibited degradation, Eicosanoid Activity Induction involves initiation of the biological function of hormone-like endogenous unsaturated and oxygenated fatty acid derivatives of arachidonic acid (eicosanoids) that act near the site of synthesis and have a specific regulatory effect on the activity of target cells in host defense reactions, immediate hypersensitivity, and inflammation. Eicosanoids include prostaglandins, leukotrienes, thromboxanes, and hydroxyeicosatetraenoic acid compounds. 